\title{
Demonstration of A Satellite-Based Index To Monitor Habitat at Continental-Scales
}

Nicholas C. Coops ${ }^{1 *}$, Michael A. Wulder ${ }^{2}$, Donald Iwanicka ${ }^{1}$

1- Department of Forest Resource Management, 2424 Main Mall, University of

British Columbia, Vancouver, British Columbia, Canada V6T 1 Z4

2-Canadian Forest Service (Pacific Forestry Center), Natural Resources Canada, Victoria, British Columbia, Canada V8Z 1M5

$\left.{ }^{*}\right)$ corresponding author:

Nicholas C. Coops

Phone: (604) 822 6452, Fax (604) 822-9106, Email: nicholas.coops@ubc.ca

\section{Pre-print of published version.}

\section{Reference:}

Coops, N.C., Wulder, M.A., Iwanicka, D. 2008. Demonstration of a satellitebased index to monitor habitat at continental-scales. Ecological Indicators 9: 948-958

\section{DOI:}

doi:10.1016/j.ecolind.2008.11.003

\section{Disclaimer:}

The PDF document is a copy of the final version of this manuscript that was subsequently accepted by the journal for publication. The paper has been through peer review, but it has not been subject to any additional copy-editing or journal specific formatting (so will look different from the final version of record, which may be accessed following the DOI above depending on your access situation). 


\section{ABSTRACT}

An important initial step in the conservation and sustainable management of the Earth's biodiversity is to implement systems to both identify and subsequently monitor components of biological diversity, along with developing a better understanding of the processes that significantly threaten their conservation or sustainable use. Key factors in both species diversity and richness are related to environmental heterogeneity which is driven by temporal and spatial variation in the biological, physical, and chemical features of the environment. These environmental characteristics are manifest through the condition and change in vegetation productivity (considered as an integrated response of vegetation to climate and soil conditions). Earth observation is uniquely capable of synoptically covering large areas of the planet in a repeatable, and cost effective manner, and is a well established technology for detecting terrestrial vegetation productivity. A recently developed Dynamic Habitat Index (DHI), based on satellite observations of the fraction of radiation absorbed by the canopy (fPAR), has been shown to effectively cluster remotely sensed observations into a range of habitat regimes which in turn have been related to breeding bird surveys in the Canadian Province of Ontario and across the conterminous United States. With evidence that the index is well correlated with species diversity, we consider, in this subsequent paper, whether such an index is a suitable candidate as a continental index to characterize and subsequently monitor habitat conditions. To do so, we first utilise available fPAR data available from 2000 - 2005 over North America, and apply the index. Using information on continental terrestrial ecozones and their ecological distinctiveness, we then compare and contrast the index and utilize trajectory analysis to assess what changes 
have occurred in the index over the 6-year time period and possible implications for continental biodiversity. The potential application of the index is the discussed.

Key words: Habitat; productivity; vegetation dynamics; large-area; ecozone; biodiversity; biological distinctiveness; North America; cluster analysis; dynamic habitat index; MODIS; fPAR, 


\section{INTRODUCTION}

There is global consensus that the present loss of biodiversity is inextricably linked with human development, and that the conservation and sustainable use of our remaining biological diversity is critical for both current and future generations of life on Earth (UNEP, 2002). An important initial step in understanding what terrestrial biological diversity exists is for resource agencies to implement systems which can identify and monitor components of biological diversity, along with the processes that significantly threaten their conservation (CBD, 1992). This challenge has led to an increased awareness of the need for relevant biological indicators from which biodiversity can be measured (Leyequien et al., 2007) with indicators such as species, habitats, and ecoregional characteristics, which can be sampled in the field, categorized, and subsequently interpreted, often promoted as critical information layers in ongoing decision making.

Spatial, environmental, heterogeneity is one of the driving factors explaining species richness (Stoms and Estes, 1993) with increases in heterogeneity associated with richer species assemblages when compared to simple ecosystems (Simpson, 1949; Huston, 1994). This has principally been attributed to the creation of niche differentiation between species with the variation in resources allowing competing species to partition more effectively (Leyequien et al., 2007; Loreau, 1998). Factors contributing to environmental heterogeneity include the temporal and spatial variation in the biological, physical, and chemical components of the environment (Leyequien et al., 2007) which in turn manifests itself through changes in vegetation productivity and biomass due the 
integrated response of vegetation to climate and soil conditions. A direct link between productivity and species richness, distribution and abundance of individuals is therefore expected, and has been demonstrated (Currie, 1991; Gaston and Blackburn, 2000; Oindo and Skidmore, 2002; Walker et al., 1992; Nightingale et al., 2008).

The link between landscape productivity and fauna species richness is essentially an ecological one, based principally on food to meet metabolic requirements and habitat for shelter and nesting (Berry et al., 2007). The movement and migration of fauna in particular is governed by the provision of food and habitat with the shape and size of individuals home ranges a fundamental ecological parameter for modeling of species (Herfindal et al., 2005). Understanding species spatial distributions is therefore important for management and conservation to ensure there is a correspondence, for example between size of management unit and the home range of the species they are designed to conserve (Herfindal et al., 2005). In addition, information on the spatial scale at which management decisions are made is also critical for deriving population estimates using either formal population viability approaches or when simply extrapolating from surveys of species distributions (Nilsen et al., 2005). Unlike plant species distributions however, faunal home ranges vary by orders of magnitude for different species groups due to differences in body size, feeding behaviour, and habitat. Furthermore, substantial variation can exist within a single species, with home ranges and populations varying by factors of 10 to 1000 (Gompper and Gittleman, 1991) depended on the productivity of the area. The temporal as well as the spatial variations in the distribution and productivity of vegetation is therefore directly lined to both the persistence and existence of fauna. 
The task of identifying and monitoring biodiversity at large, regional or national scales, using traditional surveying techniques such as ground or aerial overview surveying, remains logistically difficult and financially prohibitive and as a result there remains a paucity of data on continental and global patterns of species distributions (Brooks et al., 2002). Earth observation data is uniquely capable of synoptically covering large areas of the planet in a repeatable and cost effective manner. Data from these satellite sensors has already provided significant insights into biological diversity and the underlying ecological processes (Berry and Roderick, 2002; Running et al., 2004; Turner et al., 2003). Satellite remote sensing has been shown to be effective at the broad scale detection and delineation of anthropogenic and natural disturbances driving the loss of global biological diversity (Achard et al., 2002; Potter et al., 2003). In particular, remote sensing offers the capacity to monitor vegetation productivity at a number of temporal and spatial scales (Potter et al., 2003; Running et al., 2004, Fraser and Latifovic, 2005; Coops et al., 2006). In addition, vegetation readily reflects disturbance events such as fire, blow down, harvested, or consumed by herbivores making it an ideal indicator of landscape condition and as such provides an important way to evaluate the current landscape production as well as provide a mechanism to detect changes in habitat due to disturbance.

One key approach to monitor the terrestrial environment is to compute and monitor the Normalized Difference Vegetation Index (NDVI), a normalized ratio of the red and infrared reflectance channels, as it provides an indication of photosynthetic activity of 
chlorophyll based vegetation (Tucker, 1979) has been used extensively to predict biophysical parameters of forests (Wulder, 1998), and as a means of examining how environmental changes affect the distribution of both plants and animals (Pettorelli et al., 2005). For example a long term archive of NDVI data derived from the Advanced Very High Resolution Radiometer (AVHRR) onboard the NOAA satellites, has been successfully used to provide estimates of the inter-annual variability of global vegetation activity and to link broad scale changes in NDVI to climate drivers (Myneni et al., 1998). More recently, the Enhanced Vegetation Index (EVI), a similar index, but one less affected by the atmosphere or soil effects, has also been related to production, both regionally and globally (Huete et al., 2002). For mammals increased levels of vegetation production as predicted from NDVI have been linked with increases in mammal abundance including ostrich and wildebeest (Verlinden and Masogo, 1997) and higher NDVI values have also been associated with seasonal migration of herds of wildebeest in the Serengeti-Mara (Musiega and Kazadi, 2004). Skidmore et al. (2003) compared both avian and mammalian species richness with the NDVI however found that in general climatic parameters were in a general a better predictor of species richness than satellite derived NDVI. The relationship between annual vegetative biomass (derived from NDVI) and avian species diversity was assessed in Senegal (Jorgensen and Nohr, 1996) with some success with strong relationships between satellite greenness and bird species richness. Similarly Hurlbert and Haskell (2003) found, at fine spatial scales, NDVI to be a good predictor of species richness and habitat heterogeneity a better predicted of species richness at more coarse spatial resolutions. Similarly Hawkins et al. (2003) found that both satellite derived and climatic 
productivity indicators (NDVI and actual evapo-transpiration) correlated well with bird diversity data in North America.

Another key metric of vegetation production in addition to the NDVI, is the fraction of photosynthetically active radiation (or fPAR, also sometimes called fraction of Absorbed Photosynthetically Active Radiation, fAPAR) intercepted by vegetation, which is analogous to greenness cover (Knyazikhin et al., 1998) and ranges from 0 on nonvegetated surfaces, to 1 for very dense vegetated cover. In theory, the higher the fPAR observed over a vegetation growing season, the denser the green leaf cover, the higher the productivity, and the less disturbed the vegetation cover; conversely, the lower the fPAR, the less productive the landscape. fPAR is inclined to be more linearly related, and less saturated, to higher levels of biomass than NDVI and it is estimates of fPAR that are required to estimate the rate at which carbon dioxide and sunlight are utilised during photosynthesis, over time yielding the landscape overall productivity (Monteith, 1972). Potter et al. (2003) demonstrated for example, that 10 years of global greenness observations could detect a range of ecosystem disturbances such as fire and insect infestation due to their impact on vegetation pattern. Nilsen et al. (2005) investigates measures of fauna diversity and compared the home ranges of 12 carnivore species with 2 years of satellite data to test the hypothesis of Harestad and Bunnell (1979) that species home ranges should decrease as a function of increasing productivity. The research found that the accuracy of two thirds of the species home range sizes was improved using the greenness observations. 
The Dynamic Habitat Index (DHI), originally proposed by Berry et al. (2007) and recently applied to Canada by Coops et al. (2008a), utilizes a temporal sequence of fPAR satellite observations to derive three indicators of the underlying vegetation dynamics; the total annual light absorbed by the canopy, the lowest (o minimum) level of perennial cover, and vegetation seasonality. The index has been correlated with breeding bird survey (BBS) data in the Canadian Province of Ontario (Coops et al., 2008b), and across the conterminous United States (Coops et al., 2008c). Using the Ontario BBS for data on total bird species richness, the index explained between 47 to $75 \%$ of the observed variance. Moreover, across the United States BBS derived total bird species richness was highly correlated with a number of DHI components explaining up to $88 \%$ of the observed variation. Overall, the seasonal range and spatial variation in fPAR, accounted for most of the observed patterns in bird species richness.

In both of these studies averaged multi-year DHI layers were used, with each of the three components of the index computed from the annual sequence of fPAR data, averaged over the 6 year period. Alternately, by computing the $\mathrm{DHI}$ for each year the three components of vegetation condition can be monitored in order to characterise the dynamics of the habitat conditions over time with general trends in the $\mathrm{DHI}$ across large areas a function of both climate at the broad spatial scales, with the year to year changes to be driven by weather variations, on an annual basis (Dye and Tucker, 2003). Snow cover, for instance, provides an indication of the landscapes capacity to support sufficient levels vegetated cover over the year with locations without significant snow cover after summer more likely to maintain green biomass cover into winter 
providing continual food resources and habitat. It therefore follows that variability in snow cover duration and events will impact the $\mathrm{DHI}$ components in the more northern ecosystems (Euskirchen et al., 2006). Similarly further south, changes in rainfall regimes will also influence the inter-annual variability of the $\mathrm{DHI}$ with reductions in rainfall causing local droughts and subsequent reduction in green cover and vigour.

With these factors in mind, and with evidence that the index is well correlated with avian diversity, we consider in this paper, whether such an index is a suitable candidate as a continental index of habitat conditions. To do so, we first discuss the fPAR data available for this application over North America, and briefly discuss the $\mathrm{DHI}$ index. We then apply the index at the continental scale using data acquired from $2000-2005$ and, using continental terrestrial ecozones, we then compare and contrast the index, utilizing trajectory analysis to assess what changes have occurred in the index over the 6-year time period.

\section{METHODS}

2.1 Fraction of Photosynthetically Active Radiation (fPAR) intercepted by vegetation Since the launch of the Moderate Resolution Imaging Spectroradiometer (MODIS) sensors in 2000 and 2002, we have had access to near global 1-km imagery acquired in 36 spectral bands (Heinsch et al., 2006). NASA provides a suite of data products, based on MODIS data, on a routine basis, including FPAR, which is calculated from daily surface reflectances in a more rigorous manner than previously was the case with other sensors (Tian et al., 2000). To minimize atmospheric variation, such as cloud, and other 
confounding environmental conditions such as snow, a maximum daily fPAR approach is undertaken to derive 8-day composites. fPAR 8-day mosaics of North America from 2000 to 2005 were made available from the Goddard Flight Space Center (Gao et al., 2008). These fPAR data were processed using the TIMESAT (Jonsson and Eklundh, 2004) approach which fits a asymmetric Gaussian curve through the temporal sequence of fPAR data to remove or replace observations which were cloud contaminated or acquired under poor illumination and geometric conditions as detailed in Gao et al. (2008). The approach produces temporally smoothed, and spatially complete, MODIS estimates. As discussed by Gao et al. (2008) the approach produces estimates, when compared to data with high quality data flags, of higher quality than the initial raw observations. A total of 468 -day composites were analysed for each year resulting a total of 276 processed layers. These composites were then averaged to provide monthly MODIS fPAR layers.

\subsection{The Dynamic Habitat Index (DHI)}

Mackey et al. (2004) and Berry et al. (2007) developed, using monthly satellite observations of the Australian continent, a simple integrated index designed to track landscape productivity and assess how biomass is partitioned and made available as food and other habitat resources for fauna. The underlying approach recognises that while some species reside within single ecosystems, many vertebrate and invertebrate animal species are highly mobile, principally due to requirements of habitat and food. These species can often move over large distances principally driven by seasonal changes 
(Gilmore et al., 2007). In a previous paper we documented the underlying basis of the index (Coops et al. 2008a) with a brief summary presented here. The dynamic habitat index is comprised of three indices extracted from an annual sequence of MODIS monthly fPAR data: the first, cumulative annual fPAR, provides an indication of the overall greenness of the landscape which reflects the overall potential vegetation productivity. The second computed as the minimum annual fPAR value, provides an indication of the minimum amount of vegetated cover observed at a location. This indicator is an important factor for food access and habitat with the provision of vegetated cover throughout the year providing food and habitat resources thus influencing the behavior of many herbivorous species, and ultimately, the carnivorous species which prey upon them (Schwartz et al., 2006). The third component summarises variation of the annual greenness, which is calculated as the coefficient of

variation (standard deviation divided by the mean). The seasonal changes in vegetation at a given location depends on the local climate and geography. For example, in the arctic tundra the growing season is much shorter than for the grasslands or forests in the more temperate regions. This context needs to be considered when applying and interpreting dynamic indices of habitat productivity to a given landscape, as seasonality through its impact on food and habitat resources, is likely to exert selective pressure on life history traits (Boyce, 1979).

\subsection{Ecological stratification}

To obtain descriptions of the various biomes across North America, we utilized the Terrestrial Ecoregions of North America Assessment (Ricketts et al., 1999) who defined 
116 ecoregions for the United States and Canada, and an additional 44 for Mexico at an approximate mapping scale of 1: 3,000,000. For each ecoregion a range of biological distinctiveness and conservation status indicators were extracted based on Ricketts et al. (1999). These indicators, based on Dinerstein et al. (1995), were only computed for ecozones within Canada and the United States due to information availability, and utilise five criteria to define the overall biological distinctiveness of each ecoregion. These characterization criteria include species richness and endemism which are the scaled, cumulative total, of twenty thousand range maps of seven taxonomic groups including native vascular plants, birds, butterflies, mammals, reptiles, amphibians and terrestrial molluscs. Information on the rarity of the ecological phenomena within each of the ecoregions incorporating the presence of intact vertebrate fauna, and takes into account information on breeding habitat and the dominance of distinctive habitat such as large trees.

\subsection{Analysis Strategy}

In order to assess changes in the DHI over North America, the mean of each of the three DHI components, for each year, within each of the ecoregions was computed. We first undertook cluster analysis on the 6 year means of the three $\mathrm{DHI}$ components to compare broad-scale grouping of domains with the biome classification of Ricketts et al. (1999). With confidence in the representation of ecological units using the DHI components we then calculate the Euclidian distances (or trajectory) of the centroids of the means over the 6 years. We would expect that ecoregions with the higher summed Euclidean distances are more dynamic with respect to vegetation characteristics; 
whereas, ecoregions with smaller summed Euclidean distances were indicative of ecoregions where the components of the $\mathrm{DHI}$ and thus vegetation characteristics remained essentially invariant during the time period.

\section{RESULTS}

The three components of the $\mathrm{DHI}$ for each of the years from $2000-2005$ are shown in Figure 1. Visualizing the three components of the $\mathrm{DHI}$ jointly highlights spatially where the components are correlated or differ. In this visualization, increasing intensities of seasonality were assigned to the red band, increasing annual greenness to the green

band, and increasing levels of minimum cover to the blue band. The extensive areas of light blue represented the most productive land with high minimum cover and little seasonality; whereas, the darker purple areas, dominant in arid parts of the western portion of the conterminous US, through the Chihuahuan desert in Mexico, experience low productivity, low seasonality, and low minimum cover. Bright red areas characterized the upper Great Plains (US) and the Prairies (Canada) are areas where seasonality is high, greenness moderate, and relatively low minimum cover. As would be expected, the Arctic ecozones are highly seasonal, with low minimum cover, and low productivity. In Mexico, the lighter blue areas on either coast represent the high productivity, and high minimum cover dry forests in the west and the moister forests in the east and the more tropical forests in Central America. As expected the agricultural zones and high seasonality ecological units are absent in the southern areas. 

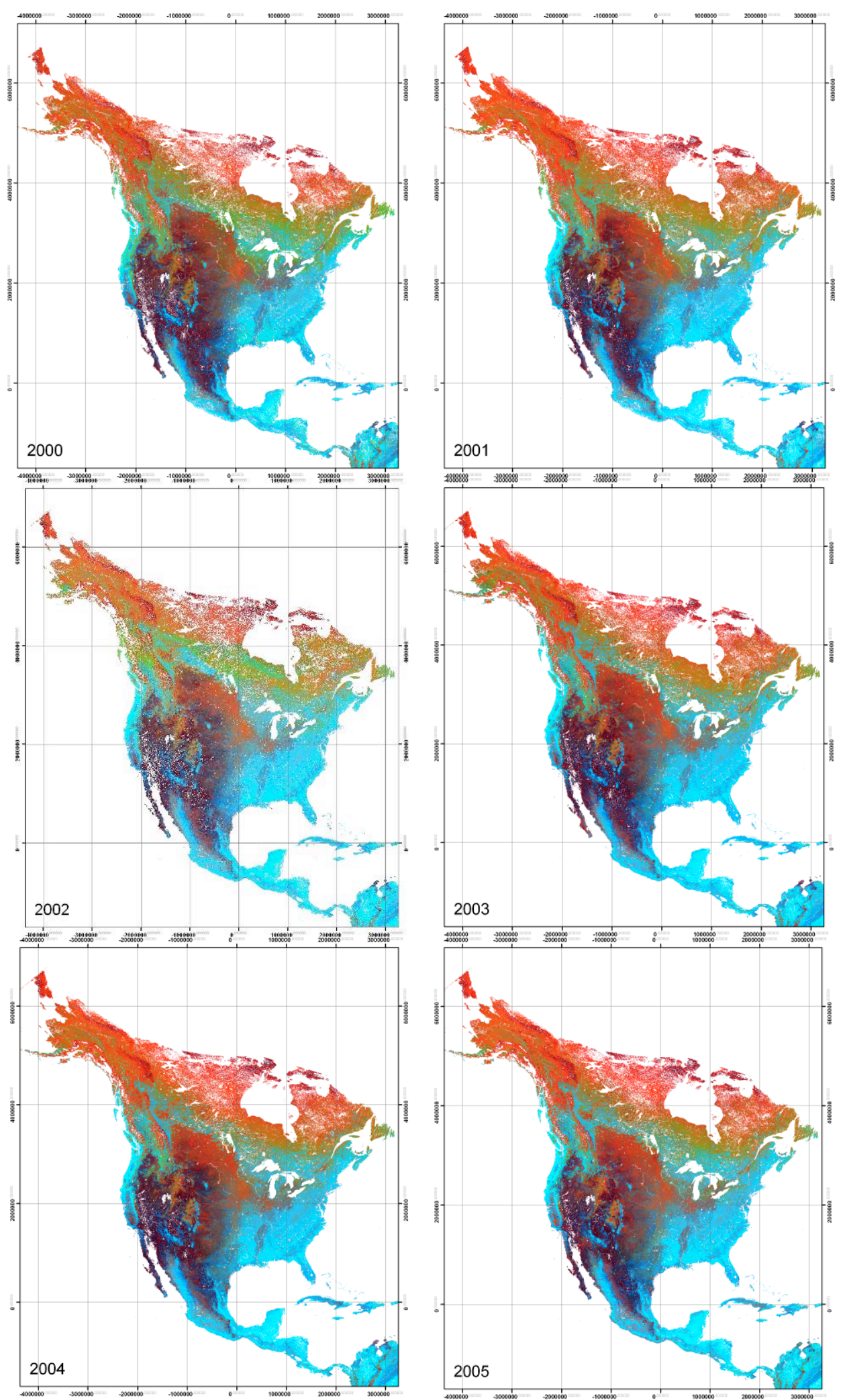

Figure 1 (a)-(e): The three components of the DHI for each of the years from $2000-2005$. Increasing intensities of seasonality were assigned to the red band, increasing annual greenness to the green band, and increasing levels of minimum cover to the blue band. The extensive light blue areas represented the most 
productive land with high minimum cover and little seasonality, whereas the darker purple areas experience low productivity, low seasonality, and low minimum cover.

Custer analysis on the mean values of the three $\mathrm{DHI}$ components for the 226 ecoregions allows a broader-scale grouping of domains to be developed from the $\mathrm{DHI}$ data, enabling comparison to the biome classification of Ricketts et al. (1999). At the eight class level, the broad-scale classification of the ecoregions based on the three $\mathrm{DHI}$ components is shown in Figure 2a, and the biome classification of Ricketts et al. (1999) shown in Figure 2b. The mean and variance of the DHI components for each of the 8 classes are shown in Figure 3(a) - (c).

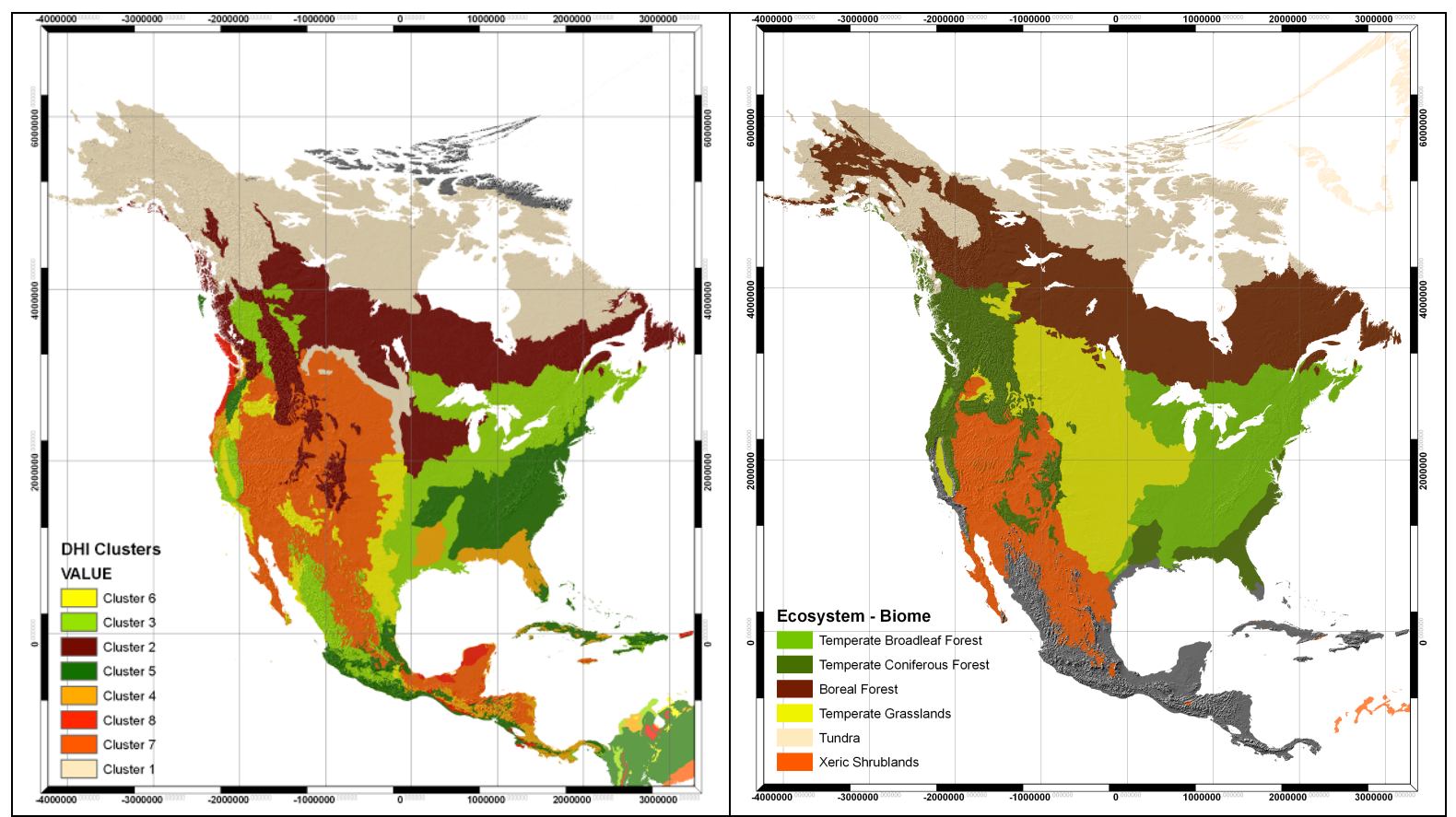

Figure 2: (a) At the eight class level, the broad-scale classification of the ecoregions based on the three DHI components and (b) the biome classification of Ricketts et al. (1999). 

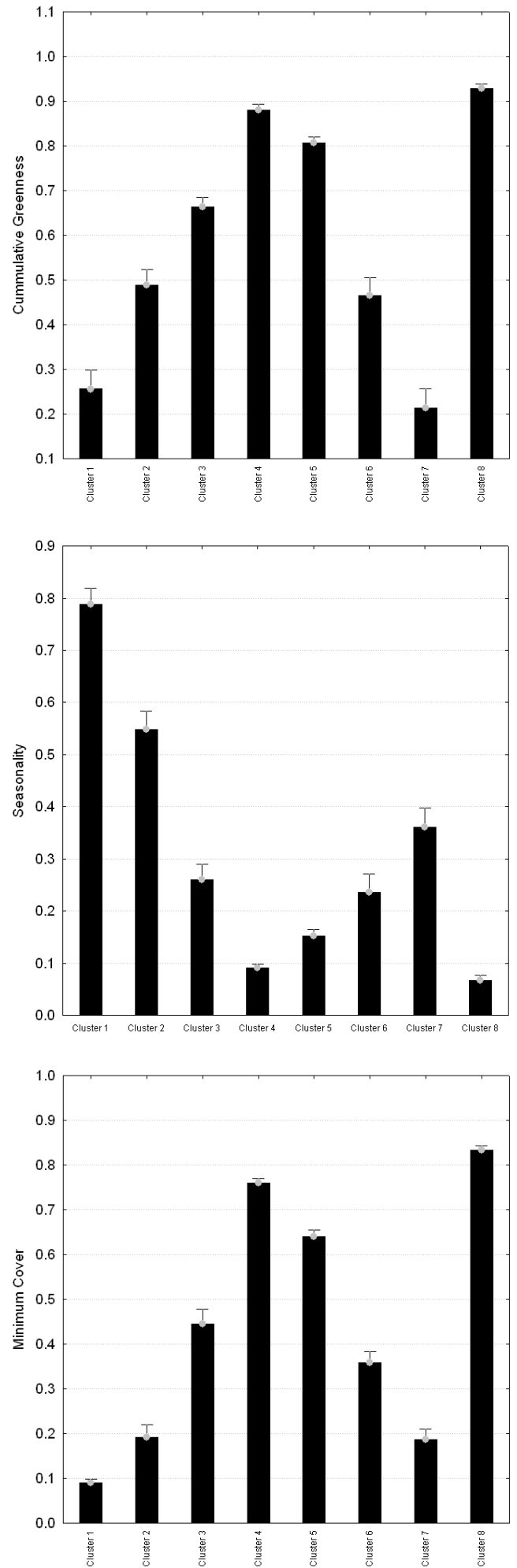

Figure 3: The mean and variance of the $\mathrm{DHI}$ components for each of the 8 classes derived form the DHI clustering. 
Figure 2 indicates that the $\mathrm{DHI}$ clustering clearly delineates the boreal forest zone and the Arctic environments. The DHI cluster 1 delineates a larger expanse of the Arctic, based on the fPAR behaviour and a smaller boreal zone (Cluster 2) than the Ricketts et al. (1999) biome classification. Examination of the individual DHI components confirm that $\mathrm{DHI}$ cluster 1 is highly seasonal with very lower annual cumulative greenness and very low levels of apparent cover, due to the snow cover through most of the year. DHI Cluster 2 also experiences high seasonality, most significantly in the north of the continent; however, higher cumulative greenness throughout the year and slightly higher levels of minimum cover indicating less snow cover.

The biome classification of Ricketts et al. (1999) defines large areas of the Pacific Northwest as temperate coniferous forest, as well as portions of the southeast of the United States. In comparison, the fPAR based clustering defines a number of smaller more regional clusters. The forests on Vancouver Island and the coastal Pacific Northwest are one unique DHI cluster (Cluster 8) typified as highly productive with a high cumulative greenness, very low seasonality and high levels of consistent vegetated cover all year. A small area in the Pacific Northwest and the central-eastern United States are also grouped as a single cluster (Cluster 5) typified again by high production with slightly increased seasonality and lower levels of minimum cover. The temperate broadleaf class in the Rickets et al. (1999) classification matches Cluster 3 well in the $\mathrm{DHI}$ cluster in the north eastern forests of the United States and spatially connected portions of southern Canada; however, some areas in the Pacific Northwest, are also included in this cluster indicating these environments follow similar fPAR patterns The 
central and western United States is classified as a single cluster, corresponding to the Xeric shrub-lands from the Ricketts et al. (1999) classification. This DHI cluster (7) has very low cumulative greenness indicating low productivity, moderate seasonality, and low levels of vegetated cover.

In order to assess how the three $\mathrm{DHI}$ components for the 266 ecozones as defined by Ricketts et al. (1999) have varied from 2000 - 2005 the Euclidian distance of the ecoregions was computed through time. Figure 4 provides a schematic of the approach with actual data of two ecoregions. As can be seen in Figure 4, ecoregion 1 (in red) has higher levels of seasonality and lower levels of greenness than ecoregion 2. However, in both cases, there have been substantial changes in the index over the 6-year period. The total length of the trajectory was computed in order to assess overall change and is shown in Figure 5. Table 1 list the Ricketts et al. (1999) ecoregions with the longest trajectories as well as information on their area, biological distinctiveness and rarity. 


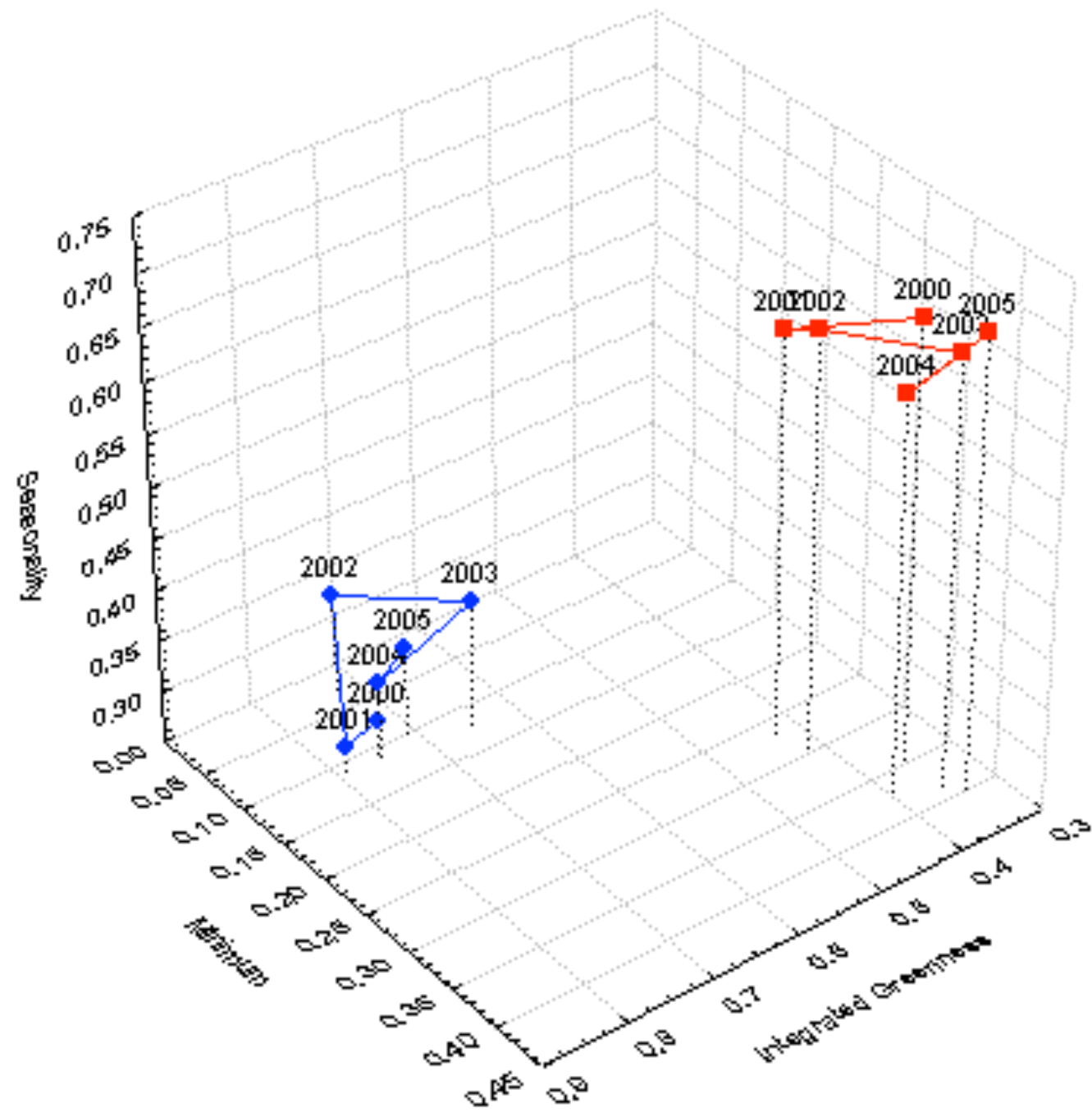

Figure 4: Schematic representation of two ecoregions and how they change over the 6 year period, with the calculation of the Euclidian distance. Ecoregion 1 (in red) has higher levels of seasonality and lower levels of greenness than ecoregion 2. However, in both cases, there has been substantial changes in the index over the 5 years period. 


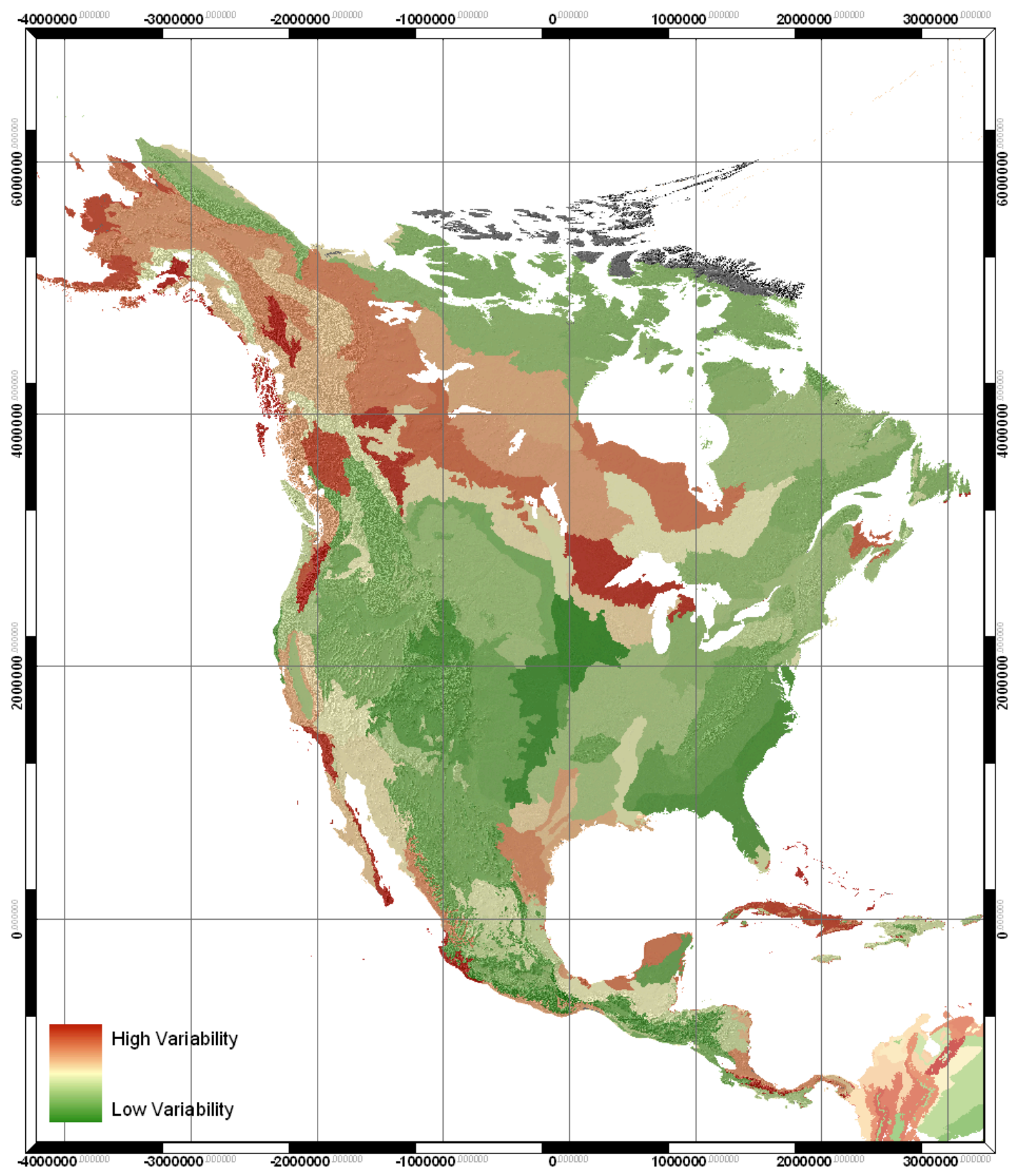

Figure 5: Ecoregions with the most change over the five years of MODIS fPAR derived continental DHI.

As Figure 5 and Table 1 show, the most dynamic ecoregions over the 6-years of MODIS fPAR data occur in coastal areas (specifically the west coast of North America, along the Baja Peninsula), the Queen Charlotte Islands, the Fraser Plateau in British Columbia, and a number of ecoregions along the Alaskan coast. Similarly a number of 
ecoregions surrounding the western portion of the Great lakes, and the tip of Labrador in Canada are also found to be highly dynamic. Of these highlighted ecoregions, a number have been classified as being globally important with respect to biological distinctiveness, for example, the Northern Pacific coastal forests, the Beringia lowland tundra, the California Coastal sage and chaparral, and the Gulf of St. Lawrence lowland forests.

Table 1: Ecoregions with the most change over the five years of MODIS fPAR derived DHI. Data on the biological distinctiveness of each of the ecoregions is also provided.

\begin{tabular}{|c|c|c|c|c|c|}
\hline Name & $\begin{array}{l}\text { Biological } \\
\text { Distinctiveness }\end{array}$ & $\begin{array}{l}\text { Species } \\
\text { Richness }\end{array}$ & Endemism & $\begin{array}{l}\text { Rare } \\
\text { Phenomena }\end{array}$ & $\begin{array}{l}\text { Rarity } \\
\text { of } \\
\text { habitat }\end{array}$ \\
\hline $\begin{array}{l}\text { South Avalon-Burin } \\
\text { oceanic barrens } \\
\text { Queen Charlotte }\end{array}$ & G & $\mathrm{L}$ & $\mathrm{L}$ & $\mathrm{N}$ & G \\
\hline $\begin{array}{l}\text { Islands } \\
\text { Sierra de la Laguna }\end{array}$ & G & $\mathrm{L}$ & $\mathrm{L}$ & $\mathrm{N}$ & G \\
\hline $\begin{array}{l}\text { pine-oak forests } \\
\text { Northern Pacific }\end{array}$ & NA & NA & NA & NA & NA \\
\hline $\begin{array}{l}\text { coastal forests } \\
\text { Sierra de la Laguna }\end{array}$ & G & L & L & $\mathrm{R}$ & $G$ \\
\hline $\begin{array}{l}\text { dry forests } \\
\text { San Lucan xeric }\end{array}$ & NA & NA & NA & NA & NA \\
\hline scrub & NA & NA & NA & NA & NA \\
\hline $\begin{array}{l}\text { Cook Inlet taiga } \\
\text { Yukon Interior dry }\end{array}$ & $\mathrm{L}$ & $\mathrm{L}$ & $\mathrm{L}$ & $\mathrm{N}$ & $\mathrm{N}$ \\
\hline forests & $\mathrm{L}$ & $\mathrm{M}$ & $\mathrm{L}$ & $\mathrm{N}$ & $\mathrm{N}$ \\
\hline $\begin{array}{l}\text { Jalisco dry forests } \\
\text { Central and Southern }\end{array}$ & NA & NA & NA & NA & NA \\
\hline $\begin{array}{l}\text { Cascades forests } \\
\text { Western Great Lakes }\end{array}$ & $\mathrm{M}$ & $\mathrm{M}$ & $\mathrm{M}$ & $\mathrm{N}$ & $\mathrm{N}$ \\
\hline $\begin{array}{l}\text { forests } \\
\text { Gulf of California }\end{array}$ & L & $M$ & $\mathrm{~L}$ & $\mathrm{~N}$ & $N$ \\
\hline $\begin{array}{l}\text { xeric scrub } \\
\text { California coastal }\end{array}$ & NA & NA & NA & NA & NA \\
\hline $\begin{array}{l}\text { sage and chaparral } \\
\text { Alberta-British } \\
\text { Columbia foothills }\end{array}$ & G & G & $\mathrm{H}$ & $\mathrm{N}$ & G \\
\hline forests & $\mathrm{L}$ & $\mathrm{L}$ & $\mathrm{L}$ & $\mathrm{N}$ & $\mathrm{N}$ \\
\hline
\end{tabular}


Fraser Plateau and

Basin complex

Beringia lowland

tundra

Araya and Paria xeric

scrub

Willamette Valley

forests

South Florida

rocklands

Gulf of St. Lawrence

lowland forests

\begin{tabular}{rrrrr|} 
L & L & L & N & N \\
$M$ & $M$ & $M$ & $R$ & $N$ \\
NA & NA & NA & NA & NA \\
$M$ & $L$ & $M$ & $N$ & $N$ \\
$H$ & $M$ & $H$ & $R$ & $N$ \\
G & L & L & N & N
\end{tabular}

Note: Biological Distinctiveness and Species Richness / Endemism, L: Low, M: Moderate, H: High, G, Globally Outstanding. Rare

Phenomena and Rarity of Habitat, N: Not rare, R: Regionally outstanding, G: Globally rare; NA: Not available

\section{DISCUSSION}

The $\mathrm{DHI}$ can be defined as an indirect approach to monitoring biodiversity (Turner et al., 2003) as it incorporates environmental parameters, including climatic and geophysical variables as well as information of vegetation production and land cover, all of which are often statistically related to species abundance or occurrence data (Nilsen et al., 2005). Employed in long time series, and encompassing North America, the DHI offers an method to develop baselines of the natural variability in productivity over a range of biogeoclimatic zones and may effectively partition the continent allowing a comprehensive, consistent, and habitat-centric understanding of the spatiotemporal variations in productivity across North America. Additionally, as the index utilizes remotely sensed measures of greenness, and by inference productivity, a link exists with previous experimental, descriptive, and theoretical work relating productivity with species richness and/or composition (Rosenzweig and Abramsky, 1993; Loreau et al., 2001). 
The use of fPAR, as opposed to other satellite measures of landscape greenness, such as NDVI, we believe strengthens the approach. MODIS predictions of fPAR are derived from physically based models of the propagation of light in plant canopies (Tian et al. 2000). As a result, the model estimates utilise many spectral bands (up to 7), not simply the red and near infrared reflectances as in the NDVI. In addition, the fPAR retrieval also considers sun angle, background reflectance, and view angle influences, whereas simple vegetation ratios do not. Nevertheless, fPAR estimates may be erroneous after a fire (Steinberg et al. 2006), or where snow accumulates in the canopy (Yang et al. 2006). Our approach to use firstly 8-day maximum composites, and secondly data smoothed using Timesat, we believe results in a less noisy, and thus more robust and consistent time series for analysis.

Analyzing temporal changes in the annual $\mathrm{DHI}$ allows ecoregions which are undergoing significant change to be effectively identified. We propose that if the $\mathrm{DHI}$ of individual ecoregions was highly variable over the 6-year analysis period, the region may have experienced, or be characterized by, variable food and habitat supply, which may lead to changes in both species abundance and the movement patterns of fauna (e.g., migration). Generally ecozones within the boreal and the arctic biomes have some of the most marked trajectories, indicative of variability in energy available. In the Arctic, annual variability in precipitation and snow fall will have significant effects on the fPAR index, due to change in the minimum cover, seasonality, and subsequently changes in annual production. As a result, areas of the Arctic which experience variability in vegetation phenology year-to-year are highlighted by the index as ecoregions 
experiencing change. Coupled with annual differences in snow cover conditions, these boreal regions of North America also form a transition between urban and agriculture land use/land cover in the south to more northerly forested regions and as a result are composed of transitional, heterogeneous, elements of both. This variation manifests itself as ecozone heterogeneity in cover and greenness characteristics spatially and temporally. In the north of the continent, such as the Boreal Plains, inter- and intraannual variation in precipitation and snowfall will impact all DHI components. Rainfall will drive, for example, summer maximum greenness for cropped areas, winter minimum greenness cover, and overall variation. In addition the mixed forest types, the transitional nature of this region from forest to agriculture, coupled with human access to forests, results in fragmented forests, with a strong seasonality component. In the west of North America areas of California, and western Mexico, along the Baja peninsula, are also highlighted as undergoing significant change over the 6-year period. This variation again can be attributed to changes in the precipitation regime over the past six years, as well as associated disturbances such as fire and drought which have resulted in noteworthy changes in the annual greenness of the landscape, and similarly changes in the seasonality.

Minimum, accumulated, and variation in satellite measured production may be combined to create integrated information, as indicated above, or may be stratified to inform on the overall potential effect on species home ranges, food supply, and habitat. This information is critical to managers charged with conserving species habitat and populations, and provides, especially over large areas, information that is otherwise 
unavailable. For instance, changes to species competitive behaviours and health have been associated with reductions in ecosystem function including drought and nutrient deficiency. As presented by Grime (1973), in temporarily resource poor environments, the competitive ability and the subsequent survival rates of species may be negatively impacted. Insights upon species composition, change, and diversity within a given area may be quantitatively produced over large areas and over-time with the $\mathrm{DHI}$ and the individual components of the index. Regional deviations are able to be delineated spatially providing information on which geographic regions are characterized by variability in energy availability and thus a methodology to track changes at continental scales through space and time. Inclusion of actual disturbance information, or through inference from multi-temporal consideration of index components, will provide additional insights to dynamics (i.e., disturbance) present that are not an on-going characteristic of the climate, vegetation, and geography as captured with the $\mathrm{DHI}$. The $\mathrm{DHI}$ provides over large areas a coarse, initial stratification of changes in habitat condition, allowing for consideration of moderate or high spatial resolution satellite imagery, combined with ground based programs, to in-turn undertake fine scale investigations of the regions of interest. The effort to compile large area coverages of higher spatial resolution imagery, such as Landsat, is not trivial in terms of time or expense (Franklin and Wulder 2002). A large area coverage will often be composed of imagery from differing seasons and years. The ability to use the information from the dense time series to guide where samples of higher spatial resolution imagery may be obtained enables economies to be developed and promotes the production of more detailed habitat or species specific information, depending on the needs of a given study. The $\mathrm{DHI}$ is derived from synoptic 
remote sensing observations it can be applied over large management units where it is not possible to undertake detailed monitoring surveys (Bailey et al., 2004), presenting an overview of habitat conditions for aiding in monitoring, decision making, or collection of additional explanatory information. The $\mathrm{DHI}$ also provides opportunities for investigation, following stratification, to examine impacts of habitat fragmentation, and land cover change, which can be related at local levels to population conditions or extinction rates (Simberloff, 1992; Brooks et al., 2002; Pimm and Raven, 2000). 


\section{ACKNOWLEDGMENTS}

This research was undertaken as part of the "BioSpace: Biodiversity monitoring with

Earth Observation data" project jointly funded by the Canadian Space Agency (CSA) Government Related Initiatives Program (GRIP), Canadian Forest Service (CFS) Pacific Forestry Centre (PFC), and the University of British Columbia (UBC). We acknowledge the work of Mackey and others at the Australian National University for communicating the initial ideas behind the habitat index. 


\section{REFERENCES}

Achard, F., Eva, H.D., Stibig, H.J., Mayaux, P., Gallego, J., Richards, T., Malingreau, J.P., 2002. Determination of Deforestation Rates of the World's Humid Tropical Forests. Science. 999-1002.

Bailey, S. A., Anderson, S., Carney, K., Cleland, E., Horner-Devine, M.C., Luck, G., Moore, L.A., Betrus, C., Fleishman, E., 2004. Primary productivity and species richness: relationships among functional guilds, residency groups and vagility classes at multiple spatial scales. Ecography. 27, 207-217.

Berry, S, Mackey, B., Brown, T., 2007. Potential applications of remotely sensed vegetation greenness to habitat analysis and the conservation of dispersive fauna. Pacific Conservation Biology. 13, 112-127

Berry, S.L., Roderick, M.L., 2002. Estimating mixtures of leaf functional types using continental-scale satellite and climatic data. Global Ecology and Biogeography. $11,23-40$.

Boyce, M. S. 1979. Seasonality and patterns of natural selection for life histories. American Naturist. 114, 569-583.

Brooks, T.M., Mittermeier, R.A., Mittermeier, C.G., da Fonseca, G.A.B., Rylands, A.B., Konstant, W.R., Flick, P., Pilgrim, J., Oldfield, S., Magin, G., Hilton-Taylor, C., 2002. Habitat loss and extinction in the hotspots of biodiversity. Conservation Biology. 16, 909-923.

CBD, 1992. Convention on Biological Diversity 1992. Article 2, Accessed 8 February 18, 2011 from: http://www.biodiv.org/convention/articles.asp 
Coops, N. C., Wulder, M.A., White, J.C., 2006. Identifying and describing forest disturbance and spatial pattern: Data selection issues and methodological implications. Chapter 2 in M. Wulder and S. Franklin, editors. Forest Disturbance and Spatial Pattern: Remote Sensing and GIS Approaches. Taylor and Francis, Boca Raton, Florida, USA, 264p.

Coops, N.C., Wulder, M.A., Duro, D.C., Han, T, and Berry. S. (2008a) Large Area Characterization Of Habitat using Satellite Data Across Canada. Ecological Indicators. 8: 754-766

Coops, N.C., Waring, R.H., Wulder, M.A., Pidgeon, A.M., Radeloff, V.C., 2008b. Bird diversity: A predictable function of satellite-derived estimates of seasonal variation in canopy light absorbance across the United States, Journal of Biogeography. (in press).

Coops, N.C., Wulder, M.A., Iwanicka, D., 2008c. Assessing the relative importance of seasonal variation in production and land cover for satellite derived predictions of breeding bird distributions over Ontario, Canada. Remote Sensing the Environment. (in review)

Currie, D.J., 1991. Energy and Large-Scale Patterns of Animal-Species and PlantSpecies Richness. American Naturalist. 137 (1), 27-49.

Dinerstein, E., Olson, D., Graham, D., Webster, A., Primm, S., Bookbinder, M., Ledec, G., 1995. A conservation assessment of the terrestrial ecoregions of Latin America and the Caribbean. World Bank, Washington, D.C.

Dye, D.G., Tucker, C.J., 2003. Seasonality and trends of snow-cover, vegetation index, and temperature in northern Eurasia, Geophysical Research Letters. 30 .1-58. 
Euskirchen, E.S., McGuire, A.D., Kicklighter, D.W., Zhuang, Q., Clein, J.S., Dargaville, R.J., Dye, D.G., Kimball, J.S., Mcdonald, K.C., Melillo, J.M., Romanovsky, V.E., Smith, N.V., 2006. Importance of recent shifts in soil thermal dynamics on growing season length, productivity, and carbon sequestration in terrestrial highlatitude ecosystems. Global Change Biology. 12, 731-750.

Franklin, S.E., Wulder, M.A. 2002. Remote sensing methods in medium spatial resolution satellite data land cover classification of large areas. Progress in Physical Geography. 26: 173-205.

Fraser, R., Latifovic, R., 2005. Mapping insect-induced tree defoliation and mortality using course spatial resolution satellite imagery. International Journal of Remote Sensing. 261, 193-200.

Gao, F., Morisette, J.T., Wolfe, R.E., Ederer, G., Pedelty, J., Masuoka, E., Myneni, R., Tan, B., Nightingale, J., 2008. An Algorithm to Produce Temporally and Spatially Continuous MODIS LAI Time Series. IEEE Geoscience and Remote Sensing Letters. 5: 60-65.

Gaston, K.J., Blackburn, T.M., 2000. Pattern and process in macroecology. Blackwell Science, Oxford.

Gilmore, S., Mackey, B., Berry, S., 2007. The extent of dispersive movement behaviour in Australian vertebrate animals, possible causes, and some implications for conservation. Pacific Conservation Biology. 13, 93-103.

Grime, J.P., 1973. Competitive exclusion in herbaceous vegetation. Nature. 242, 344347. 
Gompper, M., and J. L. Gittleman. 1991. Home range scaling: intraspecific and comparative trends. Oecologia. 87, 343-348.

Harestad, A.S., Bunnell, F.L., 1979. Home range and body weight-a re-evaluation. Ecology. 60, 389-402.

Hawkins, B.A., Porter, E.E., Diniz-Filho, J.A.F., 2003. Productivity and history as predictors of the latitudinal diversity gradient of terrestrial birds. Ecology. 84, $1608-1623$.

Heinsch, F.A., Zhao, M., Running, S.W., 2006. Evaluation of remote sensing based terrestrial productivity from MODIS using regional tower eddy flux network observations. IEEE Transactions on Geoscience and Remote Sensing. 44 (7), 1908-1925.

Herfindal, I., Linnell, J.D.C., Odden, J., Nilsen, E.B., Andersen, R., 2005. Prey density and environmental productivity explain variation in Eurasian lynx home range size at two spatial scales. Journal of Zoology. 265, 63-71.

Huete, A., Didan, K., Miura, T., Rodriguez, E.P., Gao, X., Ferreira, L.G., 2002. Overview of the Radiometric and Biophysical Performance of the MODIS Vegetation Indices. Remote Sensing of Environment. 83, 195-213.

Hurbert, A.H., Haskell, J.P., 2003. The effect of energy and seasonality on avian species richness and community composition. American Naturalist. 161 (1), 8397.

Huston, M.A., 1994: Biological Diversity. Cambridge Univ. Press, Cambridge. Jönsson, P., Eklundh, L., 2004. TIMESAT - a program for analysing time-series of satellite sensor data. Computers and Geosciences. Vol. 30, pp. 833-845. 
Jorgensen, A.J., Nohr, H., 1996. The use of satellite images for mapping of landscape and biological diversity in the Sahel. International Journal of Remote Sensing. 17, $91-109$.

Knyazikhin, Y., Kranigk, J., Myneni, R.B., Panfyorov, O., Gravenhorst, G., 1998. Influence of small-scale structure on radiative transfer and photosynthesis in vegetation cover. Journal of Geophysical Research. 103, 6133-6144.

Leyequien, E., Verrelst, J., Slot, M., Schaepman-Strub, G., Heitkönig, I.M.A., Skidmore, A.K., 2007. Capturing the fugitive: applying remote sensing to terrestrial animal distribution and diversity: review + errata. International Journal of Applied Earth Observation and Geoinformation. 9 (1), 1-20.

Loreau, M., 1998. Biodiversity and ecosystem functioning: a mechanistic model, Proc. Natl. Acad. Sci. U.S.A. 95, pp. 5632-5636.

Loreau, M., Naeem, S., Inchausti, P., Bengtsson, J., Grime, J., Hector, A., Hooper, D., Huston, M., Raffaelli, D., Schmid, B., Tilman, D., Wardle, A., 2001. Biodiversity and ecosystem functioning: current knowledge and future challenges. Science. 294, 804-808.

Mackey, B.G., Bryan, J., Randall, L., 2004. Australia's Dynamic Habitat Template 2003. In Proceedings MODIS Vegetation Workshop II University of Montana.

Monteith, J. L., 1972. Solar radiation and productivity in tropical ecosystems. Journal of Applied Ecology. 9, 747-766.

Musiega, D.E., Kazadi, S.N., 2004. Simulating the East African wildebeest migration patterns using GIS and Remote Sensing. Afr. J. Ecol. 42, 355-362. 
Myneni, R.B., Tucker, C.J., Asrar, G., Keeling, C.D., 1998. Interannual variations in satellite-sensed vegetation index data from 1981 to 1991. Journal of Geophysical Research. 103, 6145-60.

Nightingale, J.M., Fan, W., Coops, N.C., Waring, R.H., 2008. Predicting tree diversity across the USA as a function of modeled gross primary production. Ecological Applications. 18, 93-108.

Nilsen, E.B., Herfindal, I., Linnell, J.D.C., 2005 .Can intra-specific variation in carnivore home-range size be explained using remote-sensing estimates of environmental productivity? Ecoscience. 12 (1), 68-75.

Oindo, B.O., Skidmore, A.K., 2002. Interannual variability of NDVI and species richness in Kenya. International Journal of Remote Sensing. 23, 285-298.

Pettorelli, N., Vik, J. O., Mysterud, A., Gaillard, J.M., Tucker, C.J., Stenseth, N.C., 2005. Using the Satellite-Derived NDVI to Assess Ecological Responses to Environmental Change. Trends in Ecology \& Evolution. 20, 503-510.

Pimm, S.L., Russell, G., Gittleman, J.L., Brooks, T.M., 1995. The future of biodiversity. Science. 269, 347-350.

Pimm, S. L., Raven, P., 2000. Extinction by numbers. Nature. 403, 843-845.

Potter, C.S., Tan, P., Steinbach, M., Klooster, S., Kumar, V., Myneni, R., Genovese, V., 2003. Major disturbance events in terrestrial ecosystems detected using global satellite data sets. Global Change Biology. 97, 1005-1021.

Ricketts, T.H., Dinerstein, E., Olson, D.M., Loucks, C.J., Eichbaum, W., DellaSala, D., Kavanagh, K., Hedao, P., Hurley, P.T., Carney, K.M., Abell, R. and Walters, S., 1999. Terrestrial Ecoregions of North America: A Conservation Assessment. 
Island Press, Washington DC.

Rosenzweig, M.L., Abramsky, Z., 1993. How are diversity and productivity related? Pages 52-65 in R. E. Rickleffs and D. Schluter, editors. Species Diversity in Ecological Communities. University of Chicago Press 414p.

Running, S. W., Nemani, R., Heinsch, F.A., Zhao, M., Reeves, M., Hashimoto, H., 2004. A continuous satellite-derived measure of global terrestrial primary productivity: Future science and applications. Bioscience. 566, 547-560.

Schwartz, C.C., Haroldson, M.A., White, G.C., Harris, R.B., Cherry, S., Keating, K.A., Moody, D., Servheen, C., 2006. Temporal spatial and environmental influences on the demographics of grizzly bears in the Greater Yellowstone Ecosystem. Wildlife Monographs. 161, 1-68.

Simberloff, D., 1992. Do species-area curves predict extinction in fragmented forest? Pages 75-89 in T.C. Whitmore, J.A. Sayer, editors. Tropical Deforestation and Species Extinction. Chapman \& Hall 156p.

Simpson, E.H.,1949. Measurement of species diversity. Nature. 163, 688.

Skidmore, A.K., Oindo, B.O., Said, M.Y., 2003. Biodiversity assessment by remote sensing. Proceedings of the 30th International symposium on remote sensing of the environment: information for risk management and sustainable development. pp 4.

Steinberg, D.C., Goetz, S.J., \& Hyer, E. (2006) Validation of MODIS FPAR products in boreal forests of Alaska. IEEE Transactions on Geoscience and Remote Sensing, 44, 1818-1828 
Stoms, D.M., Estes, J.E., 1993. A remote-sensing research agenda for mapping and monitoring biodiversity. International Journal of Remote Sensing. 14, 1839-1860.

Tian, Y., Knyazikhin, Y., Myneni, R.B., Glassy, J.M., Dedieu, G., Running, S.W., 2000. Prototyping of MODIS LAI and FPAR algorithm with LASUR and LANDSAT data. IEEE Transactions on Geoscience and Remote Sensing, 38, 2387-2401.

Tucker, C. J., 1979. Red and photographic infrared linear combinations for monitoring vegetation. Remote Sensing of Environments. 8, 127-150.

Turner, W., Spector, S., Gardiner, N., Fladeland, M., Sterling, E., Steininger, M., 2003. Remote Sensing for Biodiversity Science and Conservation. Trends in Ecology and Evolution. 18, 306-14.

UNEP, 2002. United Nations Environmental Programme 2002: Report of the Sixth Meeting of the Conference of the Parties to the Convention on Biological Diversity (UNEP/CBD/COP/6/20). Decision VI/26, UNEP. Accessed 8 February 18, 2011 from: http://www.biodiv.org/decisions/?mZcop-06

Verlinden, A., Masogo, R., 1997. Satellite Remote Sensing of Habitat Suitability for Ungulates and Ostrich in the Kalahari of Botswana. Journal of Arid Environments. vol. 35, pp. 563-574.

Walker, R.E., Stoms, D.M., Etes, J.E., Cayocca, K.D., 1992. Relationships between biological diversity and multi-temporal vegetation index data in California. Technical Papers of the 1992 Annual Meeting of ASPRS/ACSM, Albuquerque, New Mexico, 3-7 March 1992 (Bethesda, MD: American Society for Photogrammetry and Remote Sensing), 562-571. 
Wulder, M., 1998. Optical remote sensing techniques for the assessment of forest inventory and biophysical parameters, Progress in Physical Geography. vol. 22 (4), pp. $449-476$.

Yang, W., Huang, D., Tan, B., Stroeve, J., Shabanov, N.V., Knyazikhin, Y., Nemani, R., Myneni. R.B., 2006. Analysis of Leaf Area Index and Fraction of PAR Absorbed by vegetation products from the Terra MODIS Sensor: 2000-2005. IEEE Transactions on Geoscience and Remote Sensing. 44, 1829-1842. 